\title{
Transferencias culturales, experiencias y emociones: retos y avances para el estudio de las biografías en el exilio*
}

\author{
Cultural Transfers, Experiences and Emotions: \\ Challenges and Progress in the Study of Biographies in Exile \\ CAROLINA RODRÍGUEZ-LÓPEZ \\ Universidad Complutense de Madrid \\ https://orcid.org/0000-0001-9624-3194 \\ carolinarodriguez@ghis.ucm.es \\ ANTONIO LÓPEZ VEGA \\ Universidad Complutense de Madrid \\ https://orcid.org/0000-0002-5658-8179 \\ alvega@ghis.ucm.es
}

En las biografías del siglo XX están inscritas las rupturas del siglo (...) Solo la más lejana idea de asilo podría ofrecer seguridad en la épica de las guerras mundiales (...) En esa época de guerras y revoluciones mundiales las biografías abarcan el mundo entero, y lo recorren.

(SCHLÖGEL, 2007, 364)

Todos vivimos recluidos en nuestra propia biografía

Antonio Muñoz Molina

\section{RESUMEN}

Este artículo estudia, a modo de balance, cómo el abordaje desde la biografía ha servido, dada la particular naturaleza epistemológica de la misma, para profundizar, ampliar matices y conseguir un mejor conocimiento del exilio como fenómeno historiográfico. Por otro lado, analizaremos cómo, gracias a la atención puesta en la biografía, el exilio ha podido ser investigado desde las aproximaciones metodológicas y teóricas de la historia cultural de las emociones y de la historia de las transferencias culturales. El uso preferente de la perspectiva emocional, facilita así adentrarse en una historia del exilio desde las propias biografías de los exiliados.

Palabras clave: Exilio, Historia transnacional, Historia de las emociones, Historiografía Transferencias culturales.

* Este trabajo se integra en el proyecto de investigación La biografía como género en la Edad Contemporánea: España, Argentina, México. Entidad financiadora: Ministerio de Ciencia, Innovación y Universidades. HAR 2017-89291-P. 


\begin{abstract}
In this paper the authors study how the biography approach has enabled researchers to expand nuances and achieve a deeper knowledge on exile as a historiographic phenomenon. They also analyze how, thanks to the biographical perspective, exile has also been researched from different theoretical and methodological approaches such as cultural history of emotions and history of cultural transferences. The use of emotional perspective enables historians to deepen into exile through the exiled own biographical experiences.
\end{abstract}

Keywords: Exile, Transnational History, History of emotions, Historiography Cultural Transfers.

\title{
INTRODUCCIÓN
}

Los marcos teóricos y las perspectivas de análisis en materia biográfica se han flexibilizado notablemente en la historiografía en las últimas décadas (Bruno, 2012, 113-119; Burdiel, 2014, 47-83; Morales Moya, 1987, 61-76). Desde un abordaje eminentemente político y, algo más tarde social y sociológico, el rescate de las trayectorias personales ha ido prestando cada vez mayor atención a los contextos en los que éstas se desarrollaron (personales, familiares, sociales, identitarios, profesionales, económicos, políticos...) y su interrelación en y con los mismos. Desde esos enfoques se han ido añadiendo nuevas miradas a los biografiados y, en el caso que a nosotros nos interesa, a los exiliados - tanto en su dimensión individual como colectiva-. De entre esos nuevos enfoques, para lo que aquí nos interesa conviene destacar dos: aquellos que abordan las formas en que el exilio, como proceso vital, ha sido experimentado, expresado y formulado como experiencia por sus protagonistas y, por otra parte, aquellos otros que se fijan en los mecanismos por los cuales los exiliados mantuvieron sus contactos, crearon nuevas redes (de asistencia, ayuda y colaboración y conversación) y generaron nuevas formas de vida y trabajo.

Este artículo estudiará así, por un lado, y a modo de balance, cómo el abordaje desde la biografía ha servido, dada la particular naturaleza epistemológica de la misma, para profundizar, ampliar matices y conseguir un mejor conocimiento del exilio como fenómeno historiográfico (Hernández Sandoica, 2007, 11). Por otro lado, analizaremos cómo, gracias a la atención puesta en la biografía, el exilio ha podido ser investigado desde las aproximaciones metodológicas y teóricas de la historia cultural de las emociones y de la historia de las transferencias culturales.

La posibilidad abierta por ambos planteamientos de enfocar el estudio del exilio en la vivencia y experiencia del mismo por sus protagonistas y en los intercambios culturales por ellos alentados y vehiculados sitúa sus biografías en el centro de la investigación y, obviamente también, en el centro de los grandes debates historiográficos. La reflexión sobre las escalas desde las que trabajamos los historiadores (macro, micro, global, local...) han apuntado también a la biografía como una buena forma para ampliar matices y problemáticas (Pons, 2015, 47-72). 


\section{HISTORIA BIOGRÁFICA EN LA HISTORIOGRAFÍA ESPAÑOLA}

En las décadas centrales del siglo XX, las corrientes estructuralistas y marxistas que guiaron el devenir historiográfico del mundo occidental relegaron a un segundo plano los estudios biográficos. Se produjo lo que Sabina Loriga califica como "sacrificio de la dimensión individual” $(2015,18)$, primando lo colectivo sobre lo particular, lo material sobre lo psicológico y, por tanto, la atención al sujeto solo o individuo -como desde el Romanticismo se consideraba la biografía- no tenía apenas lugar. Se consideraba que lo biográfico desbordaba la carga subjetiva del sujeto histórico y representaba un abundante caudal de vidas ejemplares cuando la historia debía atender a sociedades en su conjunto y a ciudadanos anudados a estructuras fijas y concretas.

Con todo, cierto es que el género biográfico se ha venido cultivando así desde los padres de nuestra disciplina. De manera específica, ha sido en el ámbito anglosajón donde ha alcanzado mayor fortuna. En la época contemporánea, no hay prácticamente gran personaje de la historia inglesa al que no se hayan dedicado varios estudios. Desde los memorables Vida de Samuel Johnson (1791) de James Boswell, o los Victorianos Eminentes (1918) del miembro de Bloomsbury Lytton Strachey, hasta, en periodos más actuales, los numerosos trabajos dedicados a Winston Churchill -muchos realmente consistentes, y varios auténticos monumentos del género como el de Roy Jenkins o Max Hastings- (Fusi, 2019, 5-6 y 123-134; Morales Moya, 1987, 61-76).

Fue a partir de los años ochenta cuando se ha asistido a un renacer de este género hasta conocerse nuestro tiempo como la "era de la biografía", a tenor de lo expresado por George Bowker en la última década del siglo XX (citado por Hernández Sandoica, 2007, 10). Si desde el ámbito francés, el influjo sociológico de Bourdieu llevó a sublimar el perfil sociológico de la biografía, pronto se abrieron paso nuevas narrativas biográficas desde otras latitudes donde se prestaba atención a otras dimensiones de las biografías como las emociones, los perfiles intelectuales y de pensamiento, las biografías colectivas o las biografías anónimas, entre otras muchas.

Ese tránsito -que aquí únicamente esbozamos someramente- se aprecia en la publicación, por ejemplo, de las llamadas biografías colectivas o prosopografías que salían de las coordenadas individuales para explorar una superior identidad social. Muchas biografías unidas, darían lugar a un sujeto histórico compuesto, entrelazado y, por tanto, con conciencia de causa y destino común colectivo - en lo que se aprecia una evidente resonancia marxista-. Ya no se trataba de exigir coherencia moral y ejemplaridad a individuos concretos y aislados, sino de analizar grupos, colectivos y organizaciones que se aunaban en la consecución de un fin común. También se incluyeron atenciones concretas a lo cotidiano que, vistas de manera conjunta, podían elevarse a categoría de colectivo. La inserción del tratamiento de la cotidianidad permitía, sobre todo desde la irrupción de la microhistoria, pulsar «una cadena de respuestas complejas a las provocaciones de la vida social que afrontará el sujeto en el cruce de elecciones diversas, de encrucijadas que se le dan marcadas por un sistema de valores dividido y que nunca alcanza del todo a comprender» (Hernández Sandoica, 2007, 22). 
Entre las razones que llevan a la buena salud del género biográfico, está la de su capacidad de estar presente, como ya apuntábamos, en los debates historiográficos más recientes, ofreciendo nuevas y ricas perspectivas a la agenda investigadora. La biografía es capaz así, por ejemplo, de combinarse de manera fructífera con las estrategias investigadoras de la microhistoria dado que supone «un enfoque o conjunto de enfoques que se interesan por reconstruir historias de vidas individuales como recurso (fundamental o combinado con otros) para abordar temas y problemas históricos» (Pons, 2015, 49). Esa apuesta por la reconstrucción de rasgos concretos y cotidianos ha servido, también, para sofocar un cierto cansancio por las biografías clásicas, las de los grandes hombres y sus trayectorias lineales, y para insertar en los repertorios biográficos los nombres de individuos ordinarios, en ocasiones, olvidados, segregados u oprimidos -ellos solos o vistos de manera colectiva-.

Desde estos ángulos algo más concretos, la biografía ha conseguido, asimismo, volcarse hacia una introspección y hacia un conocimiento a una escala más pequeña para cuya observación y tratamiento, para cuya interpretación -pensando en lo general-, se ha requerido también de una cierta mirada antropológica (Morales Moya, 2005, 75-86). Desde ahí tenía cabida el estudio de biografías que podríamos reconocer como especiales -únicas y/o ejemplares, para regresar así al valor primero de los estudios biográficos-, pero también aquellas otras que no resultan ni especiales, ni ejemplares, ni interesantes per se pero que, por ello precisamente, contenían un sustancial valor explicativo de una época, de un colectivo, de un proceso social, de un fenómeno o de un contexto. Así, lo privado y lo individual contribuían también a aportar retazos de vida vivida en sociedad y que, por tanto, también conformaban vida colectiva.

A la siempre presente abundancia de relatos biográficos sobre artistas, científicos, filósofos, novelistas, personalidades de las letras y de la intelectualidad, a las vidas de reyes, aristócratas, líderes de partidos, gobiernos y dictaduras, personajes muchos ellos con capacidad, incluso, para dar nombre a períodos históricos concretos, se añadieron así las biografías de figuras que fueron públicas por motivos que afectaban a la cotidianidad de una sociedad. Se unían ahí también hombres y mujeres, con una presencia cada vez más pronunciada de las segundas en el esfuerzo que, desde la profesión, se está haciendo para subsanar esta inconsistente injusticia histórica.

La estrategia para la investigación y para la exposición narrativa ha hecho, además, que los autores de biografía acudan a formatos diversos que han ido desde la biografía novelada, la llamada novela histórica -no exenta, como es sabido, de abusos intolerables para los historiadores-, hasta investigaciones amplias y de calado, con fuentes documentales viables y contrastables. Con todo, uno de los signos distintivos de la biografía -sea del tipo que sea- es el notable pulso narrativo que ha de tener atendiendo al numeroso público lector que busca historia y biografía desde el ámbito profesional, que aún rigor, metodología y que, además, no adolezcan de virtuosismo literario, marcando así tendencias, hábitos de investigación y también, por qué no decirlo, formas de escribir historia -tal vez sea el género más demandado entre potenciales lectores de historia lo que, en sí mismo, podría dar lugar a una línea de investigación en sí misma-. 
Esta nueva realidad cuenta en la historiografía española con sus caminos, fórmulas y visibilidades específicas. Si bien bebe de muy diversas fuentes -quizá la más relevante sea la influencia frances-, su elección como objeto y método con el que aportar rigor y profundidad a la disciplina, hace que la biografía ocupe un lugar destacado en el actual panorama historiográfico español (sobre las dificultades para el establecimiento de un canon en el estudio de las biografías, véase Caballé, 2015, 89-118).

Aunque podría señalarse la década de los noventa del siglo pasado como el punto de inflexión para este nuevo modo de hacer biografía, no conviene soslayar brillantes ejercicios de escritura biográfica de décadas previas, firmados por autores que pueden ser considerados padres de la biografía contemporánea española y que procedían de tradiciones historiográfica diversas. De la pluma de Jaume Vicens Vives, considerado uno de los introductores de la escuela de Annales en España salió, por ejemplo, la Historia crítica de la vida y reinado de Fernando II de Aragón en 1962. Historiadores más cercanos, inicialmente, al positivismo y abocados al estudio de las mentalidades, después, contribuyeron también a singularizar a personajes concretos de etapas muy determinantes de la historia de España. Si Gregorio Marañón publicaba en 1947 su Antonio Pérez, considerada por muchos punto de partida para acercarse al reinado de Felipe II y esencial para algunos aspectos del mismo (Fernández Álvarez, 1998, 840 y ss.), en lo que refiere a la España contemporánea, en 1951 Melchor Fernández Almagro publicó su biografía de Antonio Cánovas del Castillo y, en 1955, Jesús Pabón firmó la suya sobre Francesc Cambó. Los tres, Marañón, Almagro y Pabón, abrían múltiples vías que invitaban a revisitar a sus biografiados, seguramente entre los más analizados por la historiografía española.

Conforme a los nuevos aires a los que se asistió en nuestra historiografía cuando finalizaba el siglo pasado, historiadores muy destacados en lo social o en lo político como José Alvárez Junco, Santos Juliá, Javier Tusell o Julio Aróstegui, también se acercaron entonces a la biografía. En Alejandro Lerroux: El emperador del Paralelo (1990), Álvarez Junco se fijaba en los mecanismos con los que la demagogia populista se instaló en la política española del momento. También por entonces, Santos Juliá, se fijaba en $M a$ nuel Azaña: Una biografía política (1990) para exponer la confrontación entre el modelo de República que representaba su biografiado frente a los poderes consolidados en su tiempo como la Iglesia, el ejército, los empresarios y los partidos políticos (completaría su visión del presidente republicano en su memorable biografía de 2006). Javier Tusell (junto a José Calvo), por su parte, se acercó, primero, a Giménez Fernández: Precursor de la democracia española (1990) y prosiguió, después, con estudios sobre Franco en la Guerra Civil: Una biografía política (1992), Carrero: La eminencia gris del franquismo (1993), Antonio Maura: Una biografía política (1994) o Juan Carlos I: La restauración de la democracia (1995). Se trataba en este caso, sobre todo, de un acercamiento político, desde fuera, desde el perfil público de estos personajes, sin apenas referencias a sus rasgos psíquicos, su intimidad o su vida cotidiana (algo en lo que, por ejemplo, Pabón había incidido mucho). Así, de todos estos ejemplos que proliferaron por entonces interesa subrayar cómo sus autores se fijaron en su capacidad para influir como individuos en los 
acontecimientos decisivos de su tiempo. Siguiendo una cierta teleología orteguiana o fenomenológica, se infería de la mirada de estos autores cómo las circunstancias y voluntad de los actores de un período podían interferir de manera decisiva en el tiempo que les tocó vivir. Esas biografías, además, serían visitadas por los historiadores de manera recurrente en los siguientes años, abriéndose con ellas un fértil debate historiográfico.

Con todo, sin duda la figura que más interés suscitó entre los historiadores, por razones obvias, es la del general Franco. A su estudio han contribuido investigadores de diversas procedencias. Entre todas ellas destacan, tras la pionera biografía de Juan Pablo Fusi, Franco: Autoritarismo y poder personal (1985), la ya citada de Tusell o la de Stanley Payne, Franco: El perfil de la historia (ambas de 1992). Un año después apareció la primera de las que le dedicó Paul Preston, Franco: Caudillo de España (en adelante sería la referencia para todas las demás por su abundancia de fuentes y detalles). En 1995, sería Alberto Reig Tapia quien en Franco caudillo: Mito y realidad, abundó en el ejercicio de observación de la persona y la cimentación del mito construido en torno a la misma y, un año más tarde, en una línea similar vio la luz la de Bartolomé Bennassar (la bibliografía sobre Franco es inundatoria, se ha destacado, exclusivamente, lo más relevante historiográficamente en esa década de 1990). Más próximos a nuestro tiempo, debemos mencionar aquí, la importancia ya canónica de la biografía de Franco: Anatomía de un dictador (2018) firmada por Enrique Moradiellos (Morales Moya, 1994, 13-32 y Núñez Pérez, 1997, 407-439).

Hay también otras personalidades del ámbito político y cultural español fueron objeto desde los años 90 y continúan siéndolo de atención biográfica hasta la actualidad. El Rey Juan Carlos, por ejemplo, ha sido sujeto de atención permanente de las mismas poniendo sobre la mesa así una de las cuestiones centrales del debate sobre las biografías: $¿$ deben ser objeto de las mismas personajes ya fallecidos al tratarse estos casos de biografías inacabadas? A las que le dedicaron Charles Powell, El piloto del cambio: El rey, la monarquía y la Transición a la democracia (1991) y la ya citada de Javier Tusell de 1995, siguió una catarata de las mismas hasta hoy día -entre las publicadas ya en el siglo XXI cabe destacar la de Paul Preston, Juan Carlos: El rey de un pueblo (2003), actualizada en reiteradas ocasiones por el autor-. También Negrín, Don Juan, empresarios como Urgoiti, políticos decimonónicos como Canalejas, Sagasta, Cambó, figuras de la escena política del siglo XX tan relevantes como Claudio Sánchez Albornoz, José Antonio Primero de Rivera o Durruti, recibieron la atención de solventes especialistas que legaron biografías de alto nivel académico y divulgativo. Entre las biografías más descastadas en los últimos años, convertidas, tal vez, ya en canónicas, figuran las dedicadas a personales como Isabel II y Emilia Pardo Bazán (ambas por Isabel Burdiel), Miguel de Unamuno (Jon Juaristi y Colette y Jean-Claude Rabaté), José Ortega y Gasset (Jordi Gracia, José Lasaga, Javier Zamora Bonilla), Gregorio Marañón (Antonio López Vega) o Francisco Largo Caballero (Julio Aróstegui), por citar tan solo unos ejemplos entre los muchos sobresalientes que hacen ya que la biografía tenga, a estas alturas del siglo XXI, un lugar muy destacado en el escenario historiográfico español. 
Partiendo de estas reflexiones, de esta trayectoria marcada por los estudios biográficos y ateniendo a las múltiples aproximaciones que se han ido acumulando, en las próximas páginas, nos fijaremos en cómo las biografías de los exiliados -en concreto en el éxodo que se generó fruto de la Guerra Civil española- son buen botón de muestra, no sólo de esa explosión del género en las últimas décadas, sino también de las nuevas corrientes historiográficas que lo inspiran.

La biografía del exilio permite así, en mitad de tendencias globalizadoras de todo tipo y sin colisión con ellas, fijarse en una persona concreta y ver en ella, no uniformidad, sino un perfil poliédrico y cómo este encaja y diferencia al tiempo a esa persona en su contexto. Quien se exilia, quien se traslada, está, pues, en permanente movimiento (físico y mental) en una corriente, la del exilio, que también forma parte de la forma en que entendemos el mundo. Si, en buena medida, una biografía es metáfora de una foto fija, de un estudio de caso en un marco muy concreto y definido (Morales Moya, 2005, 75-86), una biografía en el exilio se corresponde mejor con un cuadro de Richter, en donde esa especie de imagen corrida, en movimiento continuo, encuentra -por ese mismo empujemayor precisión.

Si el hecho de estudiar una biografía implica necesariamente escribir «historia con personas» (Morales Moya, 2005, 81), que esas personas estén inmersas en un proceso de exilio nos lleva a buscar en ellas pormenores aún más específicos y matizados. El exilio siempre comienza con un acto forzado pero decidido, con una opción, una decisión y un dilema que modifican la evolución de una vida, de un destino que, hasta ese punto concreto, ese acontecimiento, parecía deducirse, derivarse naturalmente. El dilema del exiliado surge cuando, testigo y actor en su propio tiempo, ha de construir un nuevo destino inicialmente no esperado. El exiliado es, seguramente, uno de los testigos más relevadores de su tiempo y, por tanto, desde la biografía enfocada a esa vivencia y a ese tiempo, logra arrojar multitud de haces de luz para mejorar su conocimiento.

\section{BIOGRAFÍA Y EXILIO: VÍAS DE CONOCIMIENTO Y FORTALEZAS EPISTEMOLÓGICAS}

El estudio de una biografía, en las diversas circunstancias en que esa se haya desarrollado, supone prestar atención a fragmentos diferenciados de la vida de una persona, las teselas que la componen y que, en su mayoría, devienen de todo tipo de incertidumbres, miedos, intuiciones, certezas, ensayos y, también, innumerables errores. La noción de exilio es el contexto específico en el que se enmarcan las biografías que nos interesan aquí, es el factor que anuda coordenadas vitales muy precisas. Es, por decirlo de manera contundente, el acontecimiento vital de estas biografías. Al valor heurístico de la biografía como fuente de conocimiento histórico, la profundización en la etapa concreta en que el biografiado vivió un exilio sirve para abundar en la riqueza de la aproximación biográfica. Un buen ejemplo de este tipo de ejercicio lo representa la primera biografía que 
Julio Aróstegui dedicó a Largo Caballero en la que se enfocó, precisamente, en los años de exilio del político español (más tarde completaría su atención biográfica al socialista español con un nuevo y monumental trabajo, véase Aróstegui, 1990 y 2013). Apostaba el autor, por analizar las claves, políticas, personales y experienciales del exilio, por la capacidad específica que ese proceso tenía para indagar en la biografía de su exiliado.

La noción de exiliado, el participio que activa y personaliza el fenómeno del exilio, está vinculada al desplazamiento por persecución política en el siglo XX y es ya, en sí mismo una categoría de estudio. Tanto si nos aproximamos al diccionario político y social de los siglos XIX y XX español de Juan Francisco Fuentes y Javier Fernández Sebastián (2002 y 2008), como al diccionario de historia transnacional que editaron Akyra Iriye y Pierre Saunier (2009), el concepto exiliado, en su primera acepción, aparece siempre ligado a un contexto político problemático, detonador de expulsiones y salidas forzadas de población. La virulencia, cantidad, vías de tránsito e inserción hacia y en el lugar de destino, la cobertura legal para sus situaciones, y el estatus y reconocimiento de las circunstancias que rodean a los exiliados llevan a diferenciaciones conceptuales que enriquecen debates variados. Exiliado, refugiado, cerebro fugado, asilado, solicitante de asilo, miembro de una diáspora, son todos ellos términos que abarcan el campo semántico del exilio y que arrojan problemas, rasgos, perfiles, aristas, diálogos y experiencias con cabida enjundiosa en el acontecimiento vital de las vidas que biografiamos: el exilio.

El exiliado, como sujeto de un proceso hondo con múltiples facetas y problemas, es alguien marcado siempre por una decisión de origen, un dilema, aquella opción (ni fácil, ni sencilla y siempre forzada por las circunstancias) que marcan un acontecimiento vital que deriva en experiencia duradera. Como apunta Giovanni Levi, cualquier biografía está siempre abocada a «la ambigüedad de las reglas, la necesidad de tomar decisiones conscientemente en condiciones de incertidumbre», con «limitada cantidad de información que no impide, sin embargo actuar» y en la que es necesario averiguar, el «porqué de determinadas elecciones» pero «también su incidencia en el medio, su adaptación a las imposiciones venidas al individuo desde fuera, los estímulos y los límites a su capacidad de creación» (citado por Hernández Sandoica, 2004, 404). El exiliado es, en su fondo y en su definición externa, alguien siempre abonado a la incertidumbre y al dilema. Se activa así un repertorio de acciones, reacciones, vivencias y experiencias que consiguen que se delimiten dos aspectos que resultan esenciales en nuestros enfoques para conocer mejor el exilio. Nosotros partimos de la necesidad de analizar y comprender la experiencia biográfica del exiliado como agente y como productor. Como apunta Jacques Revel: «La biografía viene a ser ya no pensable bajo la única especie de la necesidad -tal vida tuvo lugar y la muerte la convirtió en destino-, sino como un campo de posibilidades entre las cuales el actor histórico tuvo que elegir» (Revel, 1996, 35).

Cualquier sujeto histórico y, tal vez con más fuerza un exiliado, enfrenta su experiencia biográfica como un conjunto de tentativas, de elecciones, de tomas de posición frente a la incertidumbre. Y el exilio, seguramente, refuerza, como en pocas circunstancias humanas, ese enfrentamiento constante con la inseguridad. Se rompen y se amplían, 
por tanto, los marcos de las biografías al uso cuando el foco está en el exilio para zafar los riesgos de tradicionales enfoques biográficos, esa forma de dejarse llevar por «modelos que asocian una cronología ordenada, una personalidad coherente y estable, con acciones sin inercia y con decisiones sin dudas" (Levi, 2019, 199), algo que Bourdieu definió muy bien como la ilusión biográfica y que suele estar repleta de simplicidades (Bourdieu, 1989, 27-33). O como sentenciaría de manera contundente Giovanni Levi:

A decir, verdad, esta simplificación supone una cierta confianza en la capacidad de la biografía para describir aquello que es significativo en una vida. Esta confianza culminará, de hecho, en el positivismo y en el funcionalismo, con los cuales la elección de hechos significativos va a acentuar el carácter ejemplar y tipológico de las biografías, privilegiando la dimensión pública frente a la dimensión privada, y rebajando a la insignificancia las desviaciones de los modelos propuestos (Levi, 2019, 199).

Desde ese ángulo, la biografía -como género, como método y como recurso- puede y debe someterse a la reflexión y mirada interdisciplinar que afecta a la historiografía entera. Desde ahí pensar

qué cosa es o debería ser una biografía permite a los historiadores trabajar en un escenario de preguntas y respuestas más complejo y consciente de sus retos, del alcance, pero también de las limitaciones, de la historia biográfica. Es decir, de aquella forma de aproximación al pasado que -centrada en trayectorias individuales- asume como propios todos y cada uno de los problemas que se plantea la historia como disciplina, agudizando la tensión analítica entre las partes y el todo, lo individual y lo colectivo, lo particular y lo general, la libertad y la necesidad (Burdiel, 2014, 14).

La biografía, la historia biográfica del exilio está así inmersa en las conversaciones historiográficas vigentes hoy día y, por eso, nosotros la incorporamos al diálogo sobre las transferencias culturales, las emociones y las experiencias.

La capacidad heurística que une atención biográfica y exilio nos lleva un poco más allá. La biografía constituye -como muy bien señala, de nuevo, Levi- «el lugar ideal para verificar el importante carácter intersticial de la libertad de la que disponen los agentes, y para observar la manera en que funcionan concretamente los sistemas normativos, que nunca están exentos de contradicciones» (Levi, 2019, 207). Cuando una persona, en las condiciones políticas impuestas que le conducen a exiliarse inicia una nueva andadura biográfica, se enfrenta, como veremos, a todo tipo de contradicciones, de elecciones posibles, deseadas, fundadas o imaginarias, a una suerte de vida en vilo que no se acaba de asentar hasta que otros mecanismos, personales, identitarios, laborales, etc., se ponen en marcha, una vida que pasa a ser vivida de veras (Gracia, 2010, 69-110.). Y todo ello, forma parte de una biografía a la que se ha añadido, súbitamente, un elemento -el del exilio-, que permite estudiar con mayor complejidad a la persona investigada. Nuestra aportación apuesta pues, siguiendo a Isabel Burdiel, por no hablar de biografía en términos generales (pensando solo en la persona, única, que queremos investigar), sino identificar 
los problemas específicos de la aproximación biográfica al caso concreto del exilio y los exiliados. Necesitamos identificar y volver a pensar las categorías capaces de explicar una trayectoria individual (o varias que se interrelacionan) y pulsar, por tanto, la capacidad de ese/esos individuo/s de ser agentes, de un proceso histórico respecto al que se elabora una problemática (en este caso, el exilio).

Una aproximación biográfica y una atención preferente a las biografías de exiliados permite, de esta manera, reunir en las diferentes dimensiones del individuo, aproximaciones, problematizaciones del sujeto y del proceso histórico que habían quedado antes compartimentadas, diferenciadas y aisladas en especialidades historiográficas poco realistas. Es la biografía, pues, un lugar de encuentro, un «observatorio privilegiado de la compleja historicidad y de la problematización de las nociones de individuo, sociedad y política; experiencia, identidad, subjetividad y objetividad; privado y público; local, nacional y global» (Burdiel, 2014, 17). A lo que cabe añadir que son las biografías en el exilio así, un escenario perfecto para ahondar en la historia transnacional por escapar el análisis de «naciones definidas por las fronteras políticas y geográficas» y por aspirar a señalar «los cruces y de intercambios» (Pons, 2015, 64).

El origen de esta atención por el exilio centrado, en el caso español, primero, en el seguimiento de personalidades clave de la política, la ciencia y la cultura, y, más tarde, en personas anónimas, podemos situarla en el hito cronológico que marcó la celebración del cincuenta aniversario del comienzo de la Guerra Civil en 1986. Pocos años antes, aparecieron los primeros estudios exhaustivos sobre el exilio, pormenorizados y recopilatorios, destacando los trabajos pioneros de José Luis Abellán (Abellán, 1978 y 1989; VVAA, 1982; Martín y Carvajal, 2006; Sánchez Cervelló, 2011; VVAA, 2012). A partir de esos primeros pasos, y con un centro muy destacado en el grupo Gexel de la Universidad de Barcelona -atento siempre al estudio del exilio literario, periodístico e intelectual en general-, Manuel Aznar ha seguido hasta la actualidad del estudio del exilio ejemplificado en casos personales -ofreciendo, en los últimos años, balances en formato diccionario, útiles y disponibles para consultas iniciales (Aznar, 1998, 2003 y 2006; Azana y LópezGarcía, 2017).

Con estos cauces abiertos, podríamos resumir -de forma sin duda injusta-, con afán de situar en sus coordenadas correctas los estudios que en España han combinado el estudio del exilio con el de las biografías, una suerte de trabajos que podemos agrupar en, al menos, bajo siete vitolas:

1.- Por un lado, aquellas investigaciones que, siguiendo perfiles personales concretos, se han centrado en observar el grado de producción científica de algunos de los más destacados representantes de la Edad de Plata española (Barona, 2003 y 2010; López Sánchez, 2013) -en algunos casos firmados por los propios protagonistas (Giral, 1994)-. Aquí podríamos también incluir a los artistas exiliados procedentes del mismo milieu intelectual (Cabañas, 1996).

2.- Grupos políticos concretos en el exilio. En este sentido ocupan un lugar especial los trabajos sobre los anarquistas españoles y la cultura del republicanismo (Alted y Domergue, 2012; Duarte, 2009). 
3.- Trabajos que atienden a los exiliados en función del lugar en el que vivieron esas etapas de sus vidas, por ejemplo, Francia, México, la URSS, los Estados Unidos y los países del Este de Europa, por solo citar unos ejemplos (Dávila, 2012; Dreyfus-Armand, 2000; Eiroa, 2018; Faber, 2002, 2008 y 2009; Gil Lázaro, 2015; Mateos, 2009; Naranjo, Luque y Puig-Samper 2002; Naranjo y Puig-Samper 2009; Ortuño, 2018; Kharinatova, 2014). Insertos con pleno derecho en la historiografía española por ocuparse de figuras relevantes del exilio español en los lugares que acogieron el mayor volumen de exiliados, son de obligada y gustosa referencia los trabajos ya clásicos de Clara Lida para México (1997) y Dora Schwarztein para Argentina (2001).

4.- El marco global de la guerra fría y la presencia y papel en él de exiliados españoles también ha tenido importante lugar en la producción historiográfica (Glondys, 2012).

5.- Merecen singularizarse también los títulos que se centran en mujeres exiliadas (Moreno Seco, 2011; Yusta, 2009) y también en los niños (Alted, Nicolás y González, 1999).

6.- También se ha problematizado convenientemente a propósito del retorno de los exiliados (Hoyos, 2013).

7.- Los títulos más recientes se han centrado en recoger, de nuevo de modo recopilatorio, los avances en la investigación respecto al exilio -singularmente al hilo de la conmemoración del 80 aniversario del exilio republicano español-. Y, con carácter singular, merece destacarse cómo se ha profundizado en el exilio de Baroja, una de las piezas claves para entender la cultura española del siglo XX (Fuster, 2019).

\section{BIOGRAFÍAS, EXILIO Y TRANSFERENCIAS CULTURALES Y CIENTÍFICAS}

La atención por la transferencia cultural y científica en el exilio nos permite observar a los exiliados como sujetos que conversan, dialogan, interactúan, reciben y aportan conocimiento. Construyen nuevos proyectos, retoman su biografía condicionados por el contexto y, también, comparten biografía con otros, con quienes -en su caso- les acompañan en el exilio y con quienes les reciben.

La confluencia entre exilio, biografía y transferencia científica y cultural está presente y ha sido practicada como vía de investigación, por ejemplo, en los estudios concernientes a los procesos exílicos del siglo XIX -los que se fijaron en las dificultades que atravesó el pensamiento liberal en Europa-. Gracias a esta perspectiva,

sabemos ahora mucho más sobre los procesos de construcción de los liberales en sus múltiples variantes, a través de la familia y la memoria transmitida, del café y las tabernas, de la prensa, de las lecturas en voz alta, de la universidad, de la ciudad o del pueblo, del exilio y de las transferencias continuas en torno a todo ello que cruzaban las fronteras europeas y americanas (Burdiel, 2014, 61). 
Las vidas en el exilio suelen ser espacios fructíferos para el intercambio y por ello es preciso que nos fijemos en esas vías por las que se comparten ideas, proyectos, conocimientos, experiencias. Así, el historiador ha de observar "la sincronía y la interacción" entre unos "individuos o grupos (los que llegan y los que les reciben, que) no son considerados solo a partir de la relación que mantienen, sino que también son vistos unos a través de los otros, en una intersección o reciprocidad que no los deja intactos ni idénticos tras los contactos experimentados, sino mestizos" (Pons, 2015, 53).

Siguiendo a Wolfgang Schmale, en el estudio de la transferencia cultural, debemos prestar atención tanto al agente de esa transferencia, como a cómo se transfiere y a qué se transfiere. Así,

the agents of cultural transfer and thus of transcultural history were ethnic or other social, religious, professional etc. groups. Among these, ethnic migration was predominant until about 1000 AD. From 1000 AD to the early 19th century, other forms, such as economic, demographic, professional and seasonal migration, were important. Since the 19th century, ethnic cleansing has played an increasingly important role, which, ran counter to transcultural history" (Schmale, 2010).

En lo que el estudio de las transferencias culturales y el exilio tiene de situar en acción, sobre todo, biografías intelectuales colectivas, podemos, también, identificar someramente aquí algunos de los trabajos que han incidido en mostrar las formas concretas en que esas transferencias se han dado y los resultados que consiguieron (Rodríguez-López y Faraldo, 2012).

Se han estudiado las empresas culturales compartidas señalando a sus iniciadores, emprendedores y protagonistas, a aquellos que dedicaron parte de sus biografías a esas iniciativas. Así, la creación la editorial Fondo de Cultura Económica, por ejemplo, va indisolublemente unida a la figura de Daniel Cosío Villegas quien, con Alfonso Reyes, fundó también La Casa de España (convertida después en El Colegio de México), y que sirvió para la acogida del exilio científico español que llegó a ese país en 1939. En el catálogo de Fondo de Cultura Económica encontramos nombres destacados del exilio español en México y de otros países de Latinoamérica cuyas investigaciones y creaciones literarias vieron la luz gracias a las cinco colecciones de esta editorial -Economía, Ciencia y Pensamiento Político, Historia, Sociología y Filosofía- y en las que también se incluyeron las traducciones de las obras que ya eran clásicas de esas disciplinas y cuya labor devendría en esencial en la formación de las elites intelectuales y científicas de la segunda mitad del siglo XX e inicios del XXI en español (Garciadiego, 2016). Más allá del universo vinculado al FCE, en México también hubo numerosos proyectos editoriales como la revista España peregrina o la editorial Séneca -donde se publicaron las obras de Antonio Machado-, por citar tan solo un ejemplo.

Por su parte, entre las empresas editoriales más destacables para el exilio español en Argentina -el otro gran núcleo de exiliados científicos y culturales de 1939-, deben mencionarse el caso de la editorial Suramericana -que publicó obra de exiliados como 
Pedro Salinas- o los proyectos surgidos en torno a Espasa-Calpe, con los ejemplos de Austral y Losada. En el caso de la segunda editorial, las diferentes colecciones que impulsó sirvieron para poner en circulación los escritos realizados en el exilio de Francisco Ayala, Luis Cernuda, Rafael Alberti, Arturo Barea, María Zambrano, Luis Araquistáin o Luis Jiménez de Asúa, entre otros muchos ${ }^{1}$.

Desde un punto de vista territorial, hay otras latitudes que merecen la atención de los historiadores de manera creciente en los últimos tiempos, pues no solo surgieron proyectos editoriales con participación de exiliados españoles en México y Argentina. En Chile, por ejemplo, la editorial Cruz del Sur -a través de sus diferentes coleccionespublicó trabajos de exiliados como Américo Castro, entre otros. Y no fueron estériles tampoco los diferentes núcleos de exiliados españoles en lugares como República Dominicana (Naranjo y Puig Samper, 2009, 87-112), en Perú -en donde, por ejemplo, fue muy fecunda la influencia de médicos españoles como Gregorio Marañón, que pasó largas temporadas allí durante sus años de exilio (López Vega, 2012)-, o en Cuba (González Lamela, 2002; Naranjo, Luque y Puig Samper, 2002).

También se ha estudiado en mayor profundidad en los últimos años la presencia de los exiliados españoles en los Estados Unidos. Así, se ha analizado, por ejemplo, la trayectoria de aquellos que acabaron ejerciendo su docencia en universidades norteamericanas, principalmente en el campo de la filología y la literatura, que obtuvieron sus plazas gracias a la intermediación de profesores ya afincados en la academia estadounidense -como Federico de Onís (Ruiz-Manjón, 2020)-, y de asociaciones educativas de talante filantrópico como el Institute of International Education -en la que intervinieron figuras como el Nobel Juan Ramón Jiménez, Américo Castro, Tomás Navarro Tomás, Ángel del Río o Fernando de los Ríos, entre otros (Zapatero, 2000; Blasco Pascual, 2001; RuizManjón, 2007).

También han aparecido trabajos que van más allá de la mirada prospectiva e indagan en la cartografía personal y emocional de los exiliados españoles en universidades norteamericanas (Rodríguez-López, 2019, 126-162). E, igualmente, se ha prestado atención a cómo ese caudal de creación, investigación y traducción que surgió a partir de los años diez del siglo XX a ambos lados del Atlántico, en no pocos casos -muy singularmente en el universo de la Revista de Occidente, en Madrid, Sur, en Buenos Aires, La Torre, en Puerto Rico, y el FCE en México- respondían a un mismo influjo cuya inspiración inicial estuvo en el círculo orteguiano en diferentes latitudes (López Vega, 2020).

\section{BIOGRAFÍA, EXILIO Y EMOCIONES}

Quienes nos enfrentamos al estudio de las biografías de exiliados trabajamos generalmente con escritos abiertos a la subjetividad, a la autorreflexión, a la introspección y

1 Véase del portal académico Editores y Editoriales Iberoamericanos. EDI-RED: http://www. cervantesvirtual.com/portales/editores_editoriales_iberoamericanos_ [Consultado 10/03/2020]. 
nos topamos enseguida con el valor cognitivo que la experiencia, la experiencia del exilio, ofrece a nuestra investigación. Así, las fuentes documentales que, de forma preferente, sirven para el estudio del exilio en profundidad son otras biografías, autobiografías, epistolarios, historias de vida, fuentes orales e, incluso, entrevistas, reportajes o colaboración en películas (Acillona, 2010; Adamez, 2017).

Seguir las reflexiones, los pasos personales y públicos de nuestros protagonistas, hacen que se desdibuje aquella idea ya cuestionada de que se pueda estudiar al biografiado como una foto fija. La aplicación de los conceptos que la historia cultural de las emociones ya ha planteado -aplicada a casos de personas biografiadas y que se enfrentaron a sus vidas en el exilio-, nos permite rescatar no sólo su capacidad de acción y relación, sino también para la construcción de identidades nuevas y múltiples. En todas esas dimensiones y capacidades, el exiliado plasma su experiencia, su vivencia concreta de lo que le acontece y, suele, además escribir y reflexionar sobre ello.

Pero sabemos, como ya se dijo, que el estudio del exilio es algo complejo y no siempre se ha tenido en cuenta el proceso de elaboración de decisiones, sino que se han construido biografías de exiliados siguiendo un itinerario lineal, forzado y simplificado, atendiendo únicamente a sus resultados finales, es decir, a los hechos. Se ha tendido a explicaciones monocausales y lineales. El exilio es algo difícil de pensar, traumático de experimentar, que genera un dolor constante en el exiliado y una herida social difícil de sanar en las sociedades que lo generan y que viene provocado por contextos y sistemas políticos concretos. Se trata de un destierro intemporal -nunca planteado como definitivo, siempre a la espera- que provoca la distancia forzosa entre el yo y el hogar. Implica la gestión de una importante carga emocional que es, en sí misma, un fenómeno que arrastra tensiones, conflictos, y que provoca dilemas -ya sea a nivel individual o colectivo- relacionados con la necesidad de sobrevivir en el tiempo. De hecho, cualquier exilio implica la nostalgia de quien lo padece con su lugar de origen, pero también, al mismo tiempo, la necesidad de adaptación al nuevo entorno en el que habitan. Ambas facetas son factores que pueden potenciar que se genere un refugio emocional (Reddy, 2001).

La decisión de salir de España -aún no se tenía del todo claro qué iba a suceder con el país, con sus ciudadanos y con la violencia acumulada en lo acabaría siendo una guerra civil-, apareció en el horizonte de muchos científicos, académicos y profesores españoles en el verano de 1936. Buscaron poner a salvo sus vidas en medio de un conflicto que se hacía cada vez más sangriento y sobre el que acabarían albergando pocas esperanzas para una salida justa. Pero buscaban también despegar, desarrollar o continuar, con algo de normalidad, las carreras académicas y científicas que habían construido en España. Querían seguir haciendo, en definitiva, aquello que sabían hacer. Necesitaron procurarse un empleo, un trabajo en alguna institución académica en el extranjero que sirviera, además, de sustento para ellos y sus familias. Querían seguir manteniendo, en lo que se pudiera, su forma de vivir, de entender la vida y de vivirse. Sus perfiles pues, como desplazados de guerra y, después, de una dictadura, tienen los rasgos que solemos atribuir a los exiliados políticos y que se mezclaron en algunos puntos con las complicaciones vitales recono- 
cibles en los emigrantes económicos. Según sus bagajes e itinerarios previos, según sus compromisos, sus militancias políticas o sus determinaciones de cualquier tipo, mantuvieron vivos rasgos de sus vidas, pero también hubieron de adaptarse y reconstruirse en la nueva situación (Rodríguez-López y Ventura, 2014, 113-138).

La salida de exiliados de España dio lugar a un mapa de geografía humana que contiene vidas, proyectos, ilusiones y miedos, que podemos explorar si situamos nuestra perspectiva en el proceso personal y colectivo experimentado por los exiliados y en sus emociones. Si nos fijamos en los que migraron a los Estados Unidos, la enorme fecundidad que muestra la perspectiva emocional amplía las posibilidades de conocer en profundidad el proceso exílico de un individuo y de un colectivo, de conocerlo como proceso conflictivo, repleto de contradicciones, y de situarlo en un espacio y en un país, sólo en parte conocido y transitado por exiliados y emigrados de todas partes del mundo (Sierra, 2013). En Norteamérica, los exiliados españoles experimentaron sufrimiento y esfuerzo emocional, encontraron refugio, construyeron comunidades emocionales y se construyeron y reconstruyeron emocionalmente. Así se muestra, por ejemplo, en concreto en la experiencia de exiliados como Pedro Salinas, Fernando de los Ríos o Américo Castro. La correspondencia e información cruzada entre ellos en su tiempo común en América nos dejan ver la experiencia vivida y su desarrollo vital (Altman, 1982, 113). Aquí utilizaremos los epistolarios, algunos editados y otros reconstruidos por nosotros a través de la investigación archivística. Se trata de las cartas escritas por los tres exiliados citados bien en su correspondencia familiar, bien en la que cruzaron con otros colegas, bien las que se intercambiaron entre ellos mismos.

Que el proceso de exilio se iniciara debido a una decisión forzada y nunca imaginada -la Guerra Civil española- conduce a identificar sin demasiado esfuerzo un buen elenco de reacciones y vivencias que exploran el fondo de la geografía humana y biográfica de los tres profesores a los que nos referimos a modo de ejemplo. Con ellos como centro de atención, podemos iluminar la correlación entre eventos activadores de emociones y de planes emprendidos tras la llegada de la emoción (Oatley, 2004).

En un comienzo, y de forma lógica en el exiliado, se advierte rabia, desazón e ira ante la injustica. Más tarde, aflora la duda, el miedo, la incertidumbre, el bloqueo y la imposibilidad de operar. Llegados al lugar donde el exilio iba a desarrollarse -al menos en su primera estación- y resueltos - o no del todo- los requisitos legales que todo desplazamiento imponía en forma de visados, permisos o salvoconductos, el desarraigo del emigrado, el vértigo ante lo desconocido, se mezclaba con las primeras nostalgias que ya nunca les abandonarían. Junto a ello, la inquietud por la ausencia de noticias de quienes quedaron en España y las primeras preguntas sobre cuánto tiempo habrían de permanecer allí.

Inmediatamente, y una vez asimilado que, al menos, tenían donde estar, llegó el choque con las costumbres del lugar de acogida - lo que en el exiliado se expresa como emoción esencial- y con ello, la sorpresa, el rechazo, la apreciación de las diferencias en las que se hallaban, en ocasiones, un lado positivo pero que también provocaron extenuación. Con el tiempo, nuestros exiliados comenzaron a ser conscientes de cuántos 
como ellos se encontraban en situación similar y, naturalmente, identificaron, asumieron o rechazaron lo que, en ese correlato de experiencias, compartían -o no- con los demás exiliados.

En procesos de exilios tan largos como el español, se desplegaron vidas enteras en tiempo, dedicación profesional y desarrollo familiar. En algunos casos, llegó un éxito que consistió, habitualmente, en buenos acomodos profesionales, el logro de un bienestar económico para la familia y la integración de ésta en la sociedad de acogida. Para quienes lo consiguieron, ese éxito no dejó de tener nunca un sabor agridulce dado que culminaba un enorme esfuerzo que permitía que el exiliado reconocerse profesionalmente con las tareas con las que siempre estuvo comprometido. En un lugar nunca imaginado, fuera del circuito acostumbrado, apartado de su cotidianidad, el exiliado, pasado el tiempo, pudo experimentar que su vida había logrado sostenerse, reconducirse y disfrutarse..., aunque siempre quedó la nostalgia con la marchó al exilio. Y aún más agridulce fue esa emoción para aquellos que fueron conscientes de que su suerte había sido mejor que la de quienes escogieron quedarse.

Naturalmente, a lo largo de la vida misma del exiliado, este elenco de emociones creció debido, entre otros factores, a su capacidad de elección, a la orientación que quiso o pudo dar a su vida, por azar, por contactos, por inclusión en redes o por propias decisiones. Así, también en lo emocional, el exilio se expresa, configura y desenvuelve como un fenómeno esencialmente transnacional y transcultural, al tiempo que permite la toma de contacto con detalles más pequeños e íntimos de la vida del exiliado, reflexiones y emociones motivadas y fraguadas en la cotidianidad del exilio (Patel, 2010; Simal, 2014; Schmale, 2010). Gracias a todos esos detalles podemos saber, por ejemplo, qué significó para ellos vivir en un lugar tan lejano y atrayente como Estados Unidos y en qué condiciones lo hicieron, cómo fue su vida diaria y cómo se mezcló en ella viejas y nuevas emociones y cómo se construyeron sus nuevas identidades (Medina-Navascués, 2007; Hammel y Grenville, 2015; Díaz Silva, 2018 y 2019).

Existen tres conceptos procedentes de la historia de las emociones que presentan una enorme potencialidad para estudiar las primeras fases de los procesos exílicos: son el de sufrimiento emocional, el de esfuerzo emocional y el de refugio emocional (Reddy, 2001). Los tres forman parte ya del utillaje teórico propio a cualquier aproximación histórico-emocional.

El primero de esos conceptos se ajusta bien al análisis de casos de personas obligadas a abandonar o a no regresar a su país de origen, dejando atrás en la mayoría de los casos la carrera profesional, la familia, los amigos.... La nota predominante durante los primeros meses del sufrimiento emocional del exilio consciente es el sentimiento de pérdida, que no remite sólo a lo material -aunque, por seguir refiriéndonos a modo de ejemplo a Salinas, Castro y de los Ríos, cunda su pena por los apuntes y las bibliotecas dejadas atrás-, sino también a lo espiritual. También acarreaban el sufrimiento de la decepción y el desgaste político y, claro, de los problemas para alcanzar un nivel de ingresos que cubriera las necesidades de sus familias -algo para lo que, en cierta manera, 
resultó importante hallar refugio en Estados Unidos, en las fórmulas profesionales que allí encontraron-.

La noción de refugio emocional hace referencia a aquellos lugares o pensamientos en los que un individuo víctima de sufrimiento encuentra alivio, aunque sea circunstancial. La construcción o hallazgo de los mismos es esencial en todo proceso de exilio dado que, en buena medida, también determina su permanencia lejos de la patria perdida. Al sufrimiento acumulado se unía la incertidumbre y las vacilaciones, ya que las preguntas no dejaron de seguir a los exiliados ni siquiera cuando sus vidas estuvieron orientadas lejos de España. Se ve, por ejemplo, en Salinas, que se plantea mil cuestiones cuando la oferta de la ampliación del contrato con el que llegó a Estados Unidos le enfrentó al conflicto emocional provocado por el exilio:

\begin{abstract}
Viviremos aquí bien, lo espero, pero siempre en el fondo de mí habrá, creo, una nostalgia por algo indefinible: la densidad, la antigüedad, de lo humano [...]. No creas que estoy desanimado, no. Aún me quedan cosas que ver aquí. Muchas. No me vengo aquí contra mi voluntad. Pero no con toda mi voluntad (Salinas, 2007, 629-630).
\end{abstract}

El concepto de comunidades emocionales reconstruye los diferentes ámbitos en los que se desenvuelve un individuo y los mecanismos mediante los cuales adapta su emocionalidad a su realidad de exiliado. También explorar las comunidades emocionales a las que se adscribieron los exiliados durante un momento u otro de su experiencia, nos hablará no sólo de su capacidad adaptativa, sus refugios y sus estrategias de identificación con la comunidad de acogida, sino también el amplio catálogo de emociones con las que se relacionaron. Una comunidad emocional se caracteriza por ser un grupo humano con un sistema de sentimientos y un código compartido (Rosenwein, 2007). A través de sus epistolario podemos también, rastrear cómo los exiliados mantuvieron su comunicación con varias comunidades emocionales a la vez de manera simultánea: la familia -si es que alguno de sus miembros no había viajado con ellos-; los compañeros de trabajo -tanto con los que habían compartido actividad en el país de origen y allí quedaron, como con los que también hubieron de marchar al exilio y con los que, o bien coincidieron en el lugar de destino, o bien, en experiencia exílica-; exiliados de otras nacionalidades; compañeros de partido, etc. Estos círculos concéntricos se convierten en sus comunidades emocionales porque, insertos en ellas, el exiliado hacía uso de un código afectivo y lingüístico referido a su experiencia, que era entendido y compartido por todos. También fue entre estas comunidades donde mejor se activaron los diálogos que facilitaron las transferencias culturales y científicas.

Las cartas que Castro y Salinas cruzaron sirven como muestra de la comunidad emocional del exilio español en Estados Unidos. Construida sobre los cimientos del antiguo Centro de Estudios Históricos donde ambos habían trabajado, se constituyó, de hecho, en una necesidad para los «españoles de esta diáspora», como reconocía Castro ya en el otoño de 1936. Esa comunidad emocional/profesional compartió cuestiones como 
las dificultades administrativas del desplazamiento. En su caso, en momentos tan complicados para moverse por el mundo, fueron frecuentes las referencias y consejos sobre las fórmulas legales exigidas para instalarse en Estados Unidos. Y a la preocupación compartida por el destino de otros colegas, se unía la celebración, íntima y compartida por esa comunidad emocional, porque en aquel contexto a ellos las cosas les iban razonablemente bien. Podían sentirse dichosos por su bienestar que, por compartido entre la comunidad emocional, resultaba alentador y menos culpable. La constitución entre los exiliados de una comunidad emocional se construyó así, a través de las cartas y de las visitas mutuas que, por razón familiar o profesional, se convirtieron entonces en la manera de «charlar, de animarnos mutuamente, de hacernos ilusiones juntos, de probarse proyectos en la opinión del amigo, en suma, de ayudarse a vivir» (Salinas, 2007, 1010).

Cada exiliado vivió su relación con otros exiliados de forma propia y cambiante en función de su proceso vital y biográfico. En el caso de Salinas, la emoción predominante fue la amargura. Consciente de que la política lo envenenaba todo («ya empieza uno a padecer lo que va a ser la cosecha terrible de la guerra: la división de todos, de todo, en dos bandos que no se perdonarán»), recibió y formuló críticas: «de lo que me quejo es de que se tome a todo el que está fuera de España como un desafectado o enemigo. Es decir, una división arbitraria y caprichosa más». Así, Salinas nunca se sintió cómodo con la que reconoció como actitud típica del exiliado español: «voy creyendo que es mejor no ver a españoles [...]. Me voy convenciendo de que la posición peor del español en el extranjero es la de que está aquí con su cuerpo [...] pero pensando en allí, en lo de allí». Se apoderó de él una mirada pesimista: «¿Qué va a quedar de España, se pregunta uno? ¡Qué horizonte! Ruinas, muertos, fieras y sometidos y humillados esclavos» (Salinas, 2007, 610, 606, 597 y 600, respectivamente).

Una navegación emocional exitosa consiste en el esfuerzo por adaptar algunas metas a la nueva situación vital al objeto de evitar el sufrimiento emocional. Un buen ejemplo de esta reconstrucción es la relación con la política que sostuvo en su exilio Fernando de los Ríos. Una relación que introdujo un elemento atípico en su proceso de reconstrucción emocional porque, al alejamiento del primer momento, siguió un nuevo compromiso más tarde. Su proceso, no obstante, no giró solamente en torno a la política y se consumó con éxito en su integración plena en la New School for Social Research y en los círculos sociales a los que tenía acceso por su condición de profesor y exiliado. En la carta que escribió a su hermano Pepe en diciembre de 1944, podemos observar quizás el que pueda considerarse mayor grado mayor de adaptación a la situación al destierro:

Te escribo el día de mis $; 65$ ! cumpleaños [...] ¡Cuánto deseo de terminar con esta dura época de interinidad! A veces me siento cansado de esta brega en tierra extraña, pero cuando me paro a considerar la diferencia de situación con respecto a los más de los desterrados, me reprocho mis murrias, porque en verdad somos afortunados entre los centenares de miles de compatriotas en el exilio. ¡Y es que algunos días siento la edad, no obstante, de estar fuerte y bien! (Muñoz Rojas, 2009, 200-201). 
De los Ríos se sintió siempre un interino en tierra ajena, pero también afortunado por la buena marcha de su carrera profesional y de las vidas de sus seres queridos. Cuando escribió esta carta, ya hacía tiempo que había vuelto a despertarse en él el interés por la política, sobre todo tras el comienzo de la Segunda Guerra Mundial: «Aun cuando yo estoy al margen de toda acción política y me limito a ayudar cuanto puedo a los refugiados, este asunto tiene dimensiones tan esencialmente humanas y dramáticas, que no quiero rehuir esfuerzo alguno que pueda servir, siquiera sea, a un intento de solución» (carta a Indalecio Prieto de enero de 1940, en la que planteaba la posible mediación de la Iglesia católica para mejorar la situación de los refugiados españoles, Prieto y de los Ríos, 2011, 60-61). De los Ríos siguió atentamente el desarrollo de la guerra y a las repercusiones que ésta podría tener sobre España: «¿podrá Franco evitar la entrada de España del lado de los alemanes? Ésta es la pregunta que me hacen muchos; mi respuesta es que no él sino el pueblo español es quien impedirá que eso ocurra», escribió en noviembre de 1942 (Muñoz Rojas, 2009, 150).

La necesaria reconstrucción emocional llevaba aparejado, además, superar las críticas, reservas y dudas que esa decisión había podido provocar entre los contemporáneos en mitad del enfrentamiento político del que tanto Salinas huía:

Parece ser que mi actitud al venirme a América es bastante discutida, por la gente
en España y se interpreta, por los que llamaríamos mis enemigos, como una huida o
prueba de falta de adhesión al gobierno. Es decir, que estoy aislado como sospechoso
por los unos y por los otros. Y por consiguiente que el día de mañana, aunque gane el
gobierno, yo que he estado en conciencia [...] más a su lado que al otro, seré mirado
con recelo. Naturalmente, yo comprendo que a los que no hemos estado allí, pasando
los sufrimientos y angustias [...] no se nos puede considerar lo mismo, y no me quejo
de eso (Salinas, 2007, 606).

La reconstrucción pasaba, igualmente, por asumir una nueva relación con el país de origen y con la nacionalidad española. Presenciar el hundimiento que se estaba produciendo llevó a Salinas al desahogo con Castro:

Mucho deseo que esté contento con su trabajo en Wisconsin, y eso le ayude en cierto modo a llevar ese peso moral de la expectativa y la angustia por las noticias de España que todos los españoles sufrimos [...]. No me indigna, tan solo, el hecho mismo, sino la indiferencia con la que el mundo civilizado contempla esos asesinatos, sin intentar forma alguna de intervención o condena. [...] Y si fuera posible renunciar, como se renuncia a una nacionalidad, a pertenecer a ella, lo haría (Salinas, 2007, 650).

Se infería de todo ello que la mejor forma de reconstruirse pasaba por mantener una relación con la nación dejada a través de la producción intelectual, de los intercambios culturales y, al mismo tiempo, por adaptarse -en la medida de lo posible- al medio americano. Para acometer lo primero, Castro animó a otros colegas españoles a unírseles en suelo americano. Que Dámaso Alonso o Rafael Lapesa participaran en los cursos 
de Middelbury College daba la posibilidad de tener «un trozo de Centro [de Estudios Históricos]» con ellos (febrero de 1948). Que un puñado de especialistas españoles se reunieran en los cursos de verano era, también para Castro, una de las mejores formas de ser «nacionales de nuestras obras» (Salinas, 2007, 650). En la adaptación era necesario superar el escollo del idioma, que agrió los primeros meses de de Salinas y De los Ríos en Estados Unidos. Y, yendo más lejos, la integración pasaba por la participación política en el país de acogida -en las elecciones de 1944, Castro pudo votar a favor de Roosevelt-.

\section{CONCLUSIONES}

La contemplación y estudio de las biografías en el exilio, desde las transferencias culturales y desde la emoción, permiten abundar en un rastro conocido por nosotros: esas vidas no conllevan ni siguen una línea recta, premeditada, previsible. Al contrario, esa mirada favorece la multiplicidad de identidades, la superposición de idas y venidas. Con esas dos perspectivas, el exilio ofrece la posibilidad de entender en una persona o en un colectivo de personas los cambios culturales que experimentaron, los intercambios que promovieron y que reorientaron sus formar de ver el mundo y entender la realidad. La experiencia y emociones que acumularon, lejos de difuminar el campo de estudio, lo interrelaciona más específicamente con la realidad.

Con la mirada emocional se consigue dejar a un lado algunos lugares comunes en el estudio de las biografías en el exilio. Se abandona la tendencia a considerar que el camino que los exiliados recorrieron puede presuponerse. Se ha solido poner el foco en un muy poco constructivo (metodológica y epistemológicamente) lo que pudo haber sido y no fue, la España que hubiera podido ser si hubieran podido seguir desarrollando sus carreras en territorio patrio. El mantenimiento de esta perspectiva presume y simplifica la dimensión experiencial del exiliado. Y, además, le exige funciones y actitudes que encajan mejor en lo que se esperaba de ellos -suponiendo, por ejemplo, que su productividad hubiera sido idéntica de haberse quedado en España en las circunstancias brindadas por la República-. Así, se considera la producción del exiliado a través del supuesto impacto que habría tenido en caso de no haber sufrido el exilio. Un contrafactual evidente que se agota al aproximarnos a las circunstancias del exiliado para vivir y adaptarse y cuando, como aquí proponemos, nos acercamos a las redes de contacto, difusión de ideas y proyectos que alimentaron eso que llamamos transferencias de ciencia, cultura y conocimiento.

Se demanda al exiliado, también, una inexcusable participación política. Se le ha tendido a presentar como agente político, como una especie de depositario consciente y activo de la memoria de la España que pudo ser y que sólo con él tenía razón de ser. Y aunque, por supuesto, mucho de esto hubo -como bien muestran innumerables títulos y trabajos-, también hubo mucho de militancia y de compromiso, de participación en organismos y empresas culturales que buscaban en todo momento recuperar y construir una mejor España. Pero esos elementos no siempre llenaron la biografía entera de los 
exiliados, ni siquiera la de los más comprometidos. Aquí la perspectiva emocional ayuda a complejizar el proceso exílico.

Se ha presumido en los exiliados, igualmente, una permanente defensa de su nacionalidad. La aproximación emocional permite matizar esta imagen del exiliado como actor en la construcción de un discurso nacional y como alguien siempre enfrentado a su decisión de emigrar y obligado a manifestarse, reflexionar y decidir sobre el ser nacional. El sufrimiento que el exilio provocó no se tradujo siempre de manera automática con la militancia/participación política, pero sí con una emoción: el dolor de la pérdida.

Salvo situaciones en las que la nostalgia del país dejado condujo a la parálisis, el exilio es más dinámico, adaptativo y fértil -vital y profesionalmente- que lo que la mirada con perspectiva únicamente nacional ofrece. En el exilio, los individuos tuvieron que reconstruirse emocionalmente y, en ello, hubo mucho también de reconstrucción nacional. Los exiliados "they have become singularities, their works have become rare and uncomfortable for nationalisms of all sign and nature, just as rare, precious and necessary for the reassessment of the European cultural history have become academic mediations like" (Valdivia, 2014).

La aproximación emocional facilita así el acercamiento a detalles de la vida del exiliado, a reflexiones y emociones motivadas por el mismo hecho de su exilio y fraguadas en el ámbito privado. Los exiliados -en las comunidades y refugios emocionales en los que desplegaron sus sentimientos-, compartieron su experiencia y dejaron constancia de detalles que permiten reconstruir su vida cotidiana, donde se mezclaban viejas y nuevas emociones.

En definitiva, no nos interesa la historia posible -muy diferente, en ocasiones, a aquella que los exiliados realmente vivían-, ni buscar en los exiliados respuestas para entender una España distinta: nos interesa la experiencia que tuvieron, no siempre la misma, a veces comparable, y siempre muy compleja. El uso preferente de la perspectiva emocional, facilita adentrarse en una historia del exilio desde las propias biografías de los exiliados. Y nos preguntamos y les preguntamos cómo gestionaron y experimentaron sus vidas y cómo se las explicaron a sí mismos, a su entorno, a quienes compartían exilio con ellos y a los que no lo hacían. No nos interesa forzarlos a ser los que fueron en 1936-1939, ni a ser alguien distinto de lo que ellos, en el mismo proceso constructivo y reconstructivo, formativo y emocional, del exilio, fueron asimilando y explicando. Una aproximación así a sus biografías nos adentra en una historia repleta, problemática, pero llena de sentido. 


\section{BIBLIOGRAFÍA}

Abellán, J. L. (dir.), El exilio español de 1939, 6 Vols., Madrid. 1976-1978.

- El exilio español en Hispanoamérica, Madrid. 1989.

Acillona, M. (ed.), Sujeto exílico: epistolarios y diarios. Exilio en primera persona, San Sebastián. 2010.

Adamez, G., Gritos de papel. Las caras de súplica del exilio español, Granada. 2017.

Alted A. y Domergue, L., La cultura del exilio anarcosindicalista español en el Sur de Francia, Madrid. 2012.

Alted, A., Nicolás E. y González R. (eds.), Los niños de la guerra de España en la Unión Soviética: de la evacuación al retorno (1937-1999), Madrid. 1999.

Altman, J. G., Epistolary: approaches to a Form, Columbus Ohio. 1982.

Aróstegui, J., Francisco Largo Caballero en el exilio. La última etapa de un líder obrero, Madrid. 1990.

- Largo Caballero. El tesón y la quimera, Barcelona. 2013.

Aznar Soler, M., El exilio literario español de 1939: actas del primer congreso internacional, Gexel. 1998.

- Los laberintos del exilio: diecisiete estudios sobre la obra literaria de Max Aub, Sevilla. 2003.

- Escritores, editoriales y revistas del exilio republicano de 1939, Sevilla. 2006.

Aznar Soler M. y López-García J. R., (Coords.), Diccionario biobibliográfico de los escritores, editoriales y revistas del exilio republicano de 1939, Sevilla. 2017.

Aznar Soler M. e Murga Castro I. (eds.), 1939. Exilio Republicano Español, Madrid. 2019.

Barona, J. L. (dir.), Ciencia, salud pública y exilio (España 1875-1939), Valencia. 2003.

- (ed.), El exilio científico republicano, Valencia. 2010.

Blasco Pascual, J., Juan Ramón Jiménez. Nueva biografía, Sevilla. 2001.

Bourdieu, P., «La ilusión biográfica», Historia y Fuente Oral, 2, 1989, pp. 27-33.

Bruno, P., «Biografía e historia: reflexiones y prácticas», Anuario IEHS, 27, 2012, pp. 113-119.

Burdiel, I., «Historia política y biografía: más allá de las fronteras», Ayer, 93, 2014 (1), pp.47-83.

Caballé, A., «La biografía en España: primeras propuestas para la construcción de un canon», en I. Burdiel y R. Foster (eds.), La historia biográfica en Europa, Zaragoza, 2015, pp. 89-118.

Cabañas, M., Artistas contra Franco. La oposición de los artistas mexicanos y españoles exiliados a las bienales hispanoamericanas de arte, México. 1996.

Collomp, C., «La porte étroite: immigration et refuge politique aux États-Unis, année 1930-1945», en C. Collomp y M. Menéndez (dirs.), Exilés et réfugés politiques aux États-Unis, 1789-2000, Paris, 2001, pp. 75-92.

Dávila Valdés, C., Refugiados españoles en Francia y México. Un estudio comparativo, México. 2012. 
Delgado, L. E.; Fernández P. y Labanyi J. (coords.), La cultura de las emociones y las emociones en la cultura (s. XVII-XVIII), Madrid. 2018.

Díaz Silva, E. Héroes, indeseables y vencidos. La quiebra y la reconstrucción del modelo de masculinidad republicano en el exilio mexicano, Granada. 2019.

- et al., Horizontes del exilio. Nuevas aproximaciones a la experiencia de los exilios entre Europa y América Latina, Madrid. 2018.

Dreyfus-Armand, G., El exilio de los republicanos españoles en Francia: de la guerra civil a la muerte de Franco, Barcelona. 2000.

Duarte, A., El otoño de un ideal. El republicanismo histórico español y su declive en el exilio de 1939, Madrid. 2009.

Eiroa, M., Españoles tras el Telón de Acero. El exilio republicano y comunista en la Europa socialista, Madrid. 2018.

Faber, S., Exile and Cultural Hegemony: Spanish intellectuals in Mexico, 1939-1975, Nashville. 2002.

- Anglo-American Hispanist and the Spanish Civil War: Hispanophilia, Commitment, and Discipline, New York. 2008.

- Contra el olvido: el exilio español en Estados Unidos, Alcalá de Henares, 2009.

Fernández Álvarez, M., Felipe II y su tiempo, Madrid. 1998.

Fernández Sebastián, J. y Fuentes, J. F. (Coords.), Diccionario Político y Social del Siglo XIX español, Madrid. 2002.

- Diccionario político y social del siglo XX español, Madrid. 2008.

Fusi, J. P., Ideas y poder. 30 biografías del siglo XX, Madrid. 2019.

Gil Lázaro, A., Inmigración y retorno. Españoles en la ciudad de México, 1900-1936, Madrid. 2015.

Fuster, F., Baroja en París: Guerra Civil y exilio (1936-1940), Madrid. 2019.

Garciadiego, J., El Fondo, La Casa y la introducción del pensamiento moderno en México, México. 2016.

Giral, J., Ciencia española en el exilio (1939-1989). El exilio de los científicos españoles, Barcelona. 1994.

Glondys, O., La guerra fría cultural y el exilio republicano español, Madrid. 2012.

González Lamela, M. P., El exilio artístico español en el Caribe: Cuba, Santo Domingo y Puerto Rico, 1936-1960, A Coruña. 2002.

Gracia, J., A la intemperie: exilio y cultura en España, Barcelona. 2010.

Hammel A. y Grenville, A., Exile and Everyday Life, Leiden. 2015.

Hernández Sandoica, E., Tendencias historiográficas actuales, Madrid. 2004.

— «La escritura biográfica», Cercles: revista d'història cultural, 10, 2007, pp. 10-25.

Hoyos, J. de, La utopía del regreso: proyecto de estado y sueños de nación en el exilio republicano en México, México. 2013.

Iriye, A. y Saunier, P. (eds.), The Palgrave Dictionary of Transnational History. From the mid-19th century to the present day, Londres. 2009.

Kharinatova, N., Edificar la cultura, construir la identidad: el exilio republicano español de 1939 en la URSS, Sevilla. 2014. 
Larraz, F., El monopolio de la palabra. El exilio intelectual en la España franquista, Madrid. 2009.

Levi, G., Microhistorias, Bogotá. 2019.

Lida, C. E., Inmigración y exilio: reflexiones sobre el caso español, México. 1997.

López Sánchez, J. M., Los refugios de la derrota. El exilio científico e intelectual republicano de 1939, Madrid. 2013.

López Vega, A., Gregorio Marañón. Radiografía de un liberal, Madrid, 2011.

- (comp.), Gregorio Marañón en el Perú, Lima, 2012.

Loriga, S., «La escritura biográfica y la escritura histórica en los siglos XIX y XX», en I. Burdiel y R. Foster (eds.), op. cit, pp. 15-46.

Martín Casas J. y Carvajal Urquijo, P., El exilio español (1936-1978), Barcelona, 2006.

Mateos, A., La batalla de México. Final de la guerra civil y ayuda a los refugiados, 19391945, Madrid. 2009.

Medina-Navascués, T., Memorias del exilio: la vida cotidiana de los primeros refugiados españoles en México, México. 2007.

Morales Moya, A., «En torno al auge de la biografía», Revista de Occidente, 74-75, 1987, pp. 61-76.

— «Formas narrativas e historiografía española», Ayer, 14,1994, pp. 13-32.

— «La historia “con personas”», en E. Hernández Sandoica y A. Langa (eds.), Sobre la historia actual. Entre política y cultura, Madrid, 2005, pp. 75-86.

Moreno Seco, M., «Las exiliadas, de acompañantes a protagonistas», Ayer, 81, 2011 (1), pp. 265-281.

Muñoz Rojas, P., Poco a poco os hablaré de todo. Historia del exilio en Nueva York de la familia De los Ríos, Giner, Urruti. Cartas, 1936-1953, Madrid. 2009.

Naranjo, C., Luque, M. D. y Puig-Samper, M. A. (eds.), Los lazos de la cultura. El Centro de Estudios Históricos de Madrid y la Universidad de Puerto Rico, Madrid. 2002.

Naranjo C. y Puig-Samper, M. A., «De isla en isla: los españoles exiliados en la República Dominicana, Puerto Rico y Cuba», Arbor. Ciencia, pensamiento y cultura, CLXXXV, enero-febrero 2009, pp. 87-112.

Núñez Pérez, M., «La biografía en la actual historiografía contemporánea española», Espacio, Tiempo y Forma, Serie V, Historia Contemporánea, 10, 1997, pp. 407-439.

Oatley, K., Emotions. A Brief History, Oxford. 2004.

Ortuño, B., Hacia el hondo bajo fondo. Inmigrantes y exiliados en Buenos Aires tras la guerra civil española, Madrid. 2018.

Patel, K. K., «Transnational History», in: European History Online (EGO), Mainz, 2010-1203.URL:http://www.ieg-ego.eu/patelk-2010-enURN:urn:nbn:de:0159-20100921314 [2020-03-30]

Pons, A., «Vidas cruzadas. Biografía y microhistoria en un mundo global», en I. Burdiel y R. Foster (eds.), op.cit, pp. 47-72.

Prieto I. y de los Ríos, F., Epistolario, 1924-1948, Madrid. 2011. 
Reddy, W., The Navigation of Feeling. A Framework for the History of Emotions, Cambridge. 2001.

Revel, J., Jeux d'échelles: la micro-analyse à l'experience, Paris. 1996.

Rodríguez-López, C., «El exilio español en las universidades estadounidenses. Cartografía humana y emocional», en M. Huguet y E. Cerdá (eds.), Miradas encontradas. Sociedades y ciudadanías en España y Estados Unidos, Madrid, 2019, pp. 126-162.

Rodríguez-López, C. y Faraldo, J. M. (eds.), Reconsidering a Lost Intellectual Project. Exiles' Reflections on Cultural Differences, Newcastle upon Tyne, 2012.

Rodríguez-López, C. y Ventura, D., «De exilios y emociones», Cuadernos de Historia Contemporánea, 36, 2014, 113-138.

Rosewein, B., Emotional Communities in the Early Middle Ages, New York. 2007.

Ruíz-Manjón, O., Fernando de los Ríos. Un intelectual en el PSOE, Madrid. 2007.

- Entre España y América. Federico de Onís (1885-1966), Salamanca. 2020.

Salinas, P., Obras Completas. Epistolario, III, Madrid. 2007.

Sánchez Cervelló, J. M., La Segunda República en el exilio, Barcelona. 2011.

Simal, J. L., «El exilio en la génesis de la nación y del liberalismo (1776-1848): el enfoque transnacional», Ayer, 94, 2014, pp. 23-48.

Schlögel, K., En el espacio leemos el tiempo, Barcelona. 2007.

Schmale, W., «A Transcultural History of Europe - Perspectives from the History of Migration», in: European History Online (EGO), Mainz 2010-12-03. URL: http:// www.iegego. eu/schmalew-2010a-en URN: urn:nbn:de:0159-20101011119 [202003-30].

Schwarzstein, D., Entre Franco y Perón: memoria e identidad del exilio republicano español en Argentina, Barcelona. 2001.

Sierra, M., Género y emociones en el romanticismo. El teatro de Bretón de los Herreros, Zaragoza. 2013.

Valdivia, P., «Review of C. Rodríguez-López y J. M. Faraldo, Reconsidering a Lost Intellectual Project: Exiles. Reflections on Cultural Differences», H-Soz-u-Kult, H-Net Reviews. June, 2014.

URL: http://www.h-net.org/reviews/showrev.php?id=42107 [2020/03/30].

VVAA., El exilio español en México, 1939-1982, México. 1982.

VVAA., El exilio republicano de 1939 y la segunda generación, Sevilla. 2012.

Yusta Rodrigo, M., Madres coraje contra Franco. La Unión de Mujeres Españolas en Francia, del antifascismo a la Guerra Fría (1941-1950), Madrid. 2009.

Zapatero, V., Fernando de los Ríos. Biografía de un intelectual, Valencia. 2000. 